\title{
A aprendizagem da leitura: o desenvolvimento da compreensão leitora
}

\section{The learning of reading: the development of reading comprehension}

\author{
Carlos Teixeira, Alda Correia \\ Escola Superior de Educação, Instituto Politécnico de Bragança, Portugal
}

\begin{abstract}
Resumo
No presente artigo problematizam-se questões referentes à didática da leitura. Descreveremos e analisaremos uma sequência de atividades pedagógicas desenvolvida, com uma turma do $5 .^{\circ}$ ano de escolaridade. Apresentamos um estudo de caso, sustentado nos princípios que regem a metodologia da investigação-ação (I-A), em três fases: A (incidente crítico), B (desenvolvimento da ação) e C (reavaliação). Os resultados evidenciam que o professor tem um papel determinante no ensino explícito de estratégias de compreensão da leitura e demonstram que a aprendizagem de estratégias optimizadoras da compreensão do texto escrito se desenvolve mediante a realização de tarefas devidamente pensadas para o efeito. Palavras-chave: Aprendizagem, leitura, compreensão, informação, esquematização.
\end{abstract}

\begin{abstract}
In this article, questions about reading didactics are discussed. We will describe and analyze a sequence of pedagogical activities developed, with a group of the 5th year of schooling. We present a case study, based on the principles governing the research-action methodology (IA), in three phases: A (critical incident), B (action development) and $\mathrm{C}$ (reevaluation). The results show that the teacher plays a decisive role in the explicit teaching of reading comprehension strategies and demonstrate that learning strategies optimizing the comprehension of written text develops through the execution of tasks properly designed for this purpose.English abstract. Two line spaces follow the abstract.

Keywords: Learning, reading, understanding, information, schematization.
\end{abstract}

A escola tem um releve papel na promoção da socialização, na luta pela integração de todos e na criação de condições favoráveis ao desenvolvimento de todas as crianças, de modo a que elas convertam informações em aprendizagens significativas. Num ensaio publicado em Sebastião da Gama - O poeta e o professor, Russo (2007) refere-se a uma passagem em que o poeta da Arrábida defendia "uma escola cujos professores fossem abertos à cultura da atualidade e entrassem na estrutura escolar para encontrar almas e não ouvidos, sendo portavozes efetivos duma escola de vida" (Gama, 2011, p. 54). A par da nossa prática pedagógica e de toda a preparação que esta exige, buscamos força e inspiração naquela que foi considerada pelo ensaísta e romancista italiano, Umberto Eco (2005), "a invenção perfeita - o livro". Em Obra Aberta (2005), Eco tornou evidente o papel ativo do leitor. Numa época em que se reconhece como vital, na vida pessoal e social, a definição de "leitura", e dos percursos envolvidos na sua aprendizagem, continua a ser o mote de muitas investigações. Para o desenvolvimento de um trabalho sistemático de compreensão de texto escrito, faz sentido planear e realizar uma ação pedagógica orientada para três tipos de atividades: atividades de pré, durante e após a leitura (Reis, et al., 2009). A partir do título ou das ilustrações pode fazer-se a antecipação de conteúdos, sendo esta uma estratégia para rever e ativar conhecimentos (Viana, et al., 2010). Quanto mais diversificado é o léxico dos alunos, maior é a sua capacidade de compreensão dos múltiplos sentidos que as palavras, já conhecidas, podem adquirir, bem como de descodificação e perceção de palavras "novas" (Sá, 2014). A ativação dos conhecimentos prévios facilita a compreensão do texto a ler, pela elaboração de conjeturas, hipóteses e questões. Relativamente às atividades a realizar durante a leitura é fundamental "ler o texto com atenção; ajustar a velocidade de leitura; sublinhar elementos do texto; tirar notas; fazer inferências, (...) criar uma imagem mental do texto lido" (Sá, 2014, pp. 155-156). As atividades devem incidir na sinopse da mensagem compreendida pela identificação das ideias fundamentais. Importa clarificar o sentido das palavras desconhecidas, recorrendo ao contexto e, se necessário, ao dicionário. É também importante não descurar a identificação do tipo ou do género textual que está a ser lido (Sá, 2014). O ensino claro destas estratégias, pelo professor, permite desenvolver e avaliar as competências de compreensão, pelo que "ninguém é competente numa área sobre a qual não detém conhecimento (...) e estes conhecimentos poderão ser aplicados em variadas situações de leitura do dia-a-dia" (Sá, 2014, p. 157). Importa de sobremaneira referir a importância da motivação para a leitura como condicionante básica para a formação de leitores fluentes. As leituras orais realizadas pelos pais ou familiares incentivam, na criança, o gosto e o desejo de se tornarem bons leitores, seguindo-lhes o exemplo (Scholes, 1989) e, em torno de quaisquer leituras, podem realizar-se muitas atividades (Sá, 2009). De acordo com Reis, et al., (2009), "convém sempre ponderar que a leitura de cada obra ou texto apresenta exigências distintas e que o mesmo texto, consoante o sujeito e o contexto de receção, pode requerer maior ou menor acompanhamento e orientação pelo professor, tanto na fase de pré-leitura 
como em modalidades de leitura apoiada (p. 103)." Os alunos devem perceber desde cedo que "para se ser leitor não basta saber ler: é preciso querer ler" (Reis, et al., 2009, p. 70). Devemos proporcionar-lhes momentos de fruição pela leitura e a partilha de vivências de leitura gratificantes para que estes leiam de modo autónomo e crítico.

\section{Estratégia de investigação e metodologia}

No âmbito da Prática de Ensino Supervisionada (PES), investigamos e aprendemos sobre o desenvolvimento da compreensão, em contexto, sendo, participantes e investigadores (Oliveira-Formosinho \& Formosinho, 2008). Realizamos um estudo de caso assente numa perspetiva de desenvolvimento do conhecimento pedagógico do conteúdo (Shulman, 1986; Shulman, 1987). Este estudo de caso segue uma metodologia qualitativa e orienta-se pelos princípios que regem a investigação-ação (I-A). A metodologia I-A permite "a compreensão aprofundada e intervenção informada, não apenas incidente na ação educativa, mas também no contexto em que essa ação se desenrola (...) através de uma metodologia em espiral de planificação, ação, observação e reflexão sobre a ação" (Carr e Kemmis, 1986, citados por Vieira e Moreira, 2011, p. 57). No dizer de Oliveira-Formosinho e Formosinho (2008), “a realidade social e educacional está pregnante de possibilidades de mudança e transformação, de que são atores centrais os profissionais quando desenvolvem a necessidade de refletir sobre a própria prática, isto é, de investigar o próprio trabalho a fim de o melhorar invocando e construindo conhecimento praxiológico" (p. 9). Em suma, a I-A possibilita a recolha de dados e faculta a oportunidade de melhoria das práticas, pelo seu caráter participativo e de colaboração e pela sua vertente nitidamente reflexiva.

\section{Instrumentos}

Delimitamos seis categorias de proficiência na realização de esquemas: 1. Fidelidade - o aluno elabora o esquema respeitando o tema do texto; 2. Distinção o aluno distingue a informação fundamental da que é acessória; 3. Sequencialidade - o aluno apresenta a informação hierarquicamente e de modo lógico; 4. Concisão - o aluno atende ao que é essencial, não repetindo informação; 5. Integridade - o aluno apresenta todas as informações importantes; 6. Legibilidade - o aluno constrói um esquema gráfico cuidado que permite entender e captar o sentido do texto.Constatamos a necessidade de definir cinco níveis de proficiência no uso de estratégias de recolha e organização da informação relevante: Nível 1 - o aluno não usa "técnicas para recolher, organizar e reter informação: sublinhar; tomar notas; esquematizar"; ou usa-as muito deficientemente, não sendo capaz de compreender as mensagens fundamentais veiculadas pelo texto. Nível 2 - o aluno usa "técnicas para recolher, organizar e reter informação: sublinhar; tomar notas; esquematizar", mas fá-lo pouco criteriosamente, pelo que revela grandes dificuldades em compreender as mensagens fundamentais do texto. Nível 3 - o aluno usa "técnicas para recolher, organizar e reter informação: sublinhar; tomar notas; esquematizar", sintetizando as ideias fundamentais do texto (distinguindo o que é essencial do que é acessório), mas não é capaz de estruturar devidamente os tópicos-chave num esquema. Nível 4 - o aluno usa "técnicas para recolher, organizar e reter informação: sublinhar; tomar notas; esquematizar", sintetizando com clareza as ideias fundamentais do texto (distinguindo o que é essencial do que é acessório), sendo capaz de estruturar devidamente os tópicos-chave num esquema. Nível 5 - o aluno usa "técnicas para recolher, organizar e reter informação: sublinhar; tomar notas; esquematizar", sintetizando com clareza as ideias fundamentais do texto (distinguindo o que é essencial do que é acessório), ordenando sequencialmente os tópicos- chaves do texto (sistematizando em esquema a informação) e sendo capaz de explicitar informação implícita no texto (ou seja faz inferência).

\section{Participantes}

A turma de $5 .^{\circ}$ ano era constituída por vinte alunos, dos quais sete eram do sexo feminino e treze eram do sexo masculino, com idades compreendidas entre os dez e os catorze anos.

\section{Procedimento}

Plano de ação - fase A: após a leitura e a exploração do capítulo I, intitulado "Fadas boas e fadas más", da obra A Fada Oriana de Sophia de Mello Breyner Andersen, distribuiu-se o guião da atividade pelos alunos, solicitando a esquematização das ideias principais do texto, seguida da explicação dos processos implícitos à sua realização, pela resposta à pergunta: Depois da leitura de um texto, o que fazes quando tens de compreender, recolher e organizar a informação relevante? Avaliamos as produções dos alunos, de 1 a 3 pontos, sendo a avaliação mínima 6 pontos e a máxima 18 pontos, conforme a figura seguinte:

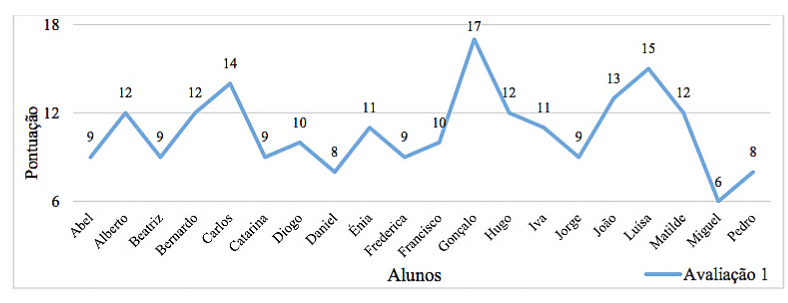

Figura 1. Avaliação das seis categorias de proficiência na realização de esquemas.

[Nota: Os nomes dos alunos são fictícios]

A média da turma foi de 10.8 valores. Não a consideramos satisfatória uma vez que é inferior a 12 valores. A análise permite concluir que $40 \%$ dos alunos (8) obteve uma avaliação entre 12 e 18 pontos. Na categoria 1, os alunos manifestaram menos dificuldades, nas restantes categorias registamos, maioritariamente, desempenhos pontuados com 1 ou 2 pontos. 
Convertemos a análise em nivéis. Nas categorias 5 e 6 , registamos as maiores dificuldades. Verificamos que $45 \%$ dos alunos se encontravam no nível 2, comparativamente com $30 \%$ que atingiam uma avaliação de nível 3. Os restantes $15 \%$ e $10 \%$ foram avaliados com o nível 1 e 4, respetivamente. Apuramos que em 7 meninas 5 atingiram o nível 2 e apenas 2 obtiveram uma avaliação de nível 3. Em relação aos meninos em 13, 3 obtiveram o nível 1, 4 o nível 2, 5 o nível 3 e apenas 1 o nível 4. A conversão das categorias em níveis resultou na figura:

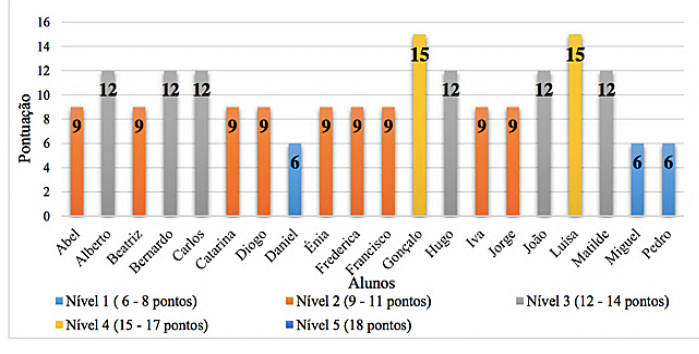

Figura 2. Conversão da avaliação das seis categorias em níveis.

As respostas à questão aberta Depois da leitura de um texto, o que fazes quando tens de compreender, recolher $e$ organizar a informação relevante?, relativa aos processos implícitos à realização dos esquemas, resultaram na seguinte tabela:

Tabela 1.

Procedimentos referidos pelos alunos

\begin{tabular}{|c|c|c|c|}
\hline Categorias & Subcategorias & Frequência absoluta $\left(n_{i}\right)$ & Frequência relativa (fi) (\%) \\
\hline \multirow{3}{*}{ Ler } & Várias vezes & 14 & 40 \\
\hline & Atentamente & 5 & 15 \\
\hline & Lentamente & 2 & 6 \\
\hline \multirow{2}{*}{ Sublinhar } & O mais importante & 2 & 6 \\
\hline & As palavras dificeis & 2 & 6 \\
\hline \multirow{3}{*}{ Compreender } & Consultar o dicionário & 4 & 12 \\
\hline & \begin{tabular}{|l|}
$\begin{array}{l}\text { Perguntar o significado } \\
\text { à professora }\end{array}$ \\
\end{tabular} & 2 & 6 \\
\hline & Entrar na história & 1 & 3 \\
\hline \multirow{2}{*}{ Sintetizar } & Fazer um esquema & 1 & 3 \\
\hline & Resumir & 1 & 3 \\
\hline TOTAL & & 34 & 100 \\
\hline
\end{tabular}

A categoria "ler" foi referida em $62 \%$ das respostas, sendo a subcategoria "várias vezes" referida $41 \%$ das vezes e as restantes subcategorias "atentamente" e "lentamente" em 21\% das respostas. Mais de 50\% dos alunos relacionou a leitura e o modo como leem com a capacidade de compreender um texto, recolher e organizar a informação relevante. Porém, constatamos que a maioria não lia com atenção efetuando, frequentemente, leituras diagonais. A categoria "sublinhar" foi mencionada em $12 \%$ das respostas e as subcategorias "o mais importante" e "as palavras difíceis" surgiram com uma percentagem de $6 \%$ cada. Comprovamos que, apesar de as subcategorias terem sido especificadas pelos alunos, quando estes tinham de o fazer sublinhavam todo o parágrafo, não distinguindo a informação relevante da acessória. A categoria "compreender" foi referida em $21 \%$ das respostas, surgindo as subcategorias "consultar o dicionário" $12 \%$ das vezes, "perguntar o significado à professora" em $6 \%$ e "entrar na história" em 3\% das respostas. As evidências da prática atestam que, embora apenas $6 \%$ das respostas refira a subcategoria "perguntar o significado à professora", deparando-se com um vocábulo desconhecido, as crianças apenas consultavam o dicionário quando incitados a fazê-lo. Importante referir que os dados evidenciarem uma conceção errada dos alunos, segundo a qual a compreensão do texto depende do conhecimento do sentido de todos os termos que ocorrem na superfície textual. A importante possibilidade que a disciplina de português proporciona, relativamente ao alargar os horizontes culturais e literários dos alunos, não foi descorada, apesar dos compromissos letivos e das nossas intenções investigacionais. No que respeita à planificação da ação pedagógica, os três importantes momentos de leitura (antes, durante e após) referidos no quadro teórico foram contemplados. Em cada momento, recorreu-se às estratégias que pareceram mais adequadas para o ensino explícito da compreensão na leitura apontadas por alguns autores de referência, como Giasson (2000; 2005), Sim-Sim, Duarte e Micaelo (2007) e Ribeiro, et al., (2010) que, a este propósito, mencionam que "o desenvolvimento da compreensão na leitura pressupõe um ensino metódico, sistemático, reflexivo, desafiante, explícito e alargado no tempo" (p. 19).

Plano de ação - fase B: Na lição n. ${ }^{\circ}$ 117/118 (plano 3), trabalhamos a compreensão inferencial e crítica a partir da banda desenhada "Capuchinho vermelho", da autoria de Quino. Intencionalmente, pretendíamos que atribuíssem sentido às ilustrações, interpretassem as indicações e as mensagens contidas em cada vinheta. A exploração pictórica demorou algum tempo e, em seguida, os alunos incluíram as falas e os pensamentos das personagens nos respetivos balões. Dialogamos, em grande grupo, acerca das possíveis leituras e introduzimos os conceitos: prancha, vinheta e tira. No final, foi lida uma proposta elaborada pela docente. Os alunos teceram comentários e partilhamos a leitura do poema "Quem és tu?" da obra A cavalo no tempo, de Luísa Ducla Soares. Conversamos acerca do materialismo, o conteúdo temático implícito à nossa interpretação da banda desenhada, assim como ao poema. Os alunos manifestaram livremente a sua opinião face ao materialismo e quiseram incluir no sumário a frase "Somos aquilo que somos e não aquilo que temos!" prova de que a aula de português, como momento cultural e de formação para os valores, funcionou.

$\mathrm{Na}$ lição n. ${ }^{\circ}$ 127/128 (plano 8), trabalhamos a compreensão literal, inferencial e crítica. Os alunos foram recebidos com a sala intencionalmente pouco iluminada e ao som de Lindsey Stirling. Estrategicamente, fomos baixando o som da melodia, para iniciarmos a leitura modelar dos capítulos VII - "A cidade" e VIII - "A árvore e os animais" de A fada Oriana. Seguiu-se a audição de uma gravação (voz da professora estagiária) do início do capítulo IX - "O abismo", à qual se seguiu a leitura dos alunos. Intencionalmente, uma parte substancial desta aula foi dedicada à leitura da obra em estudo pois pretendíamos que todos a lessem integralmente. Recorde-se que o PPEB (2009) aponta, como um descritor de desempenho do 2. ${ }^{\circ} \mathrm{CEB}$, "a leitura integral de textos literários (uma vez que conduzem ao) desenvolvimento do raciocínio inferencial e da capacidade de apreciar valores estéticos, 
éticos, culturais, presentes nos textos" (Reis, et al., 2009, p. 87). Seguiu-se o diálogo com a finalidade de atribuirmos sentido ao que lemos, identificando os possíveis ensinamentos que a obra oferece. Pretendendo que problematizassem a intriga desta narrativa, foi projetada uma imagem da obra «Narciso» (1546-48 óleo sobre tela), do pintor italiano Caravaggio e procedemos à sua leitura, cruzando-a com a interpretação do texto lido. Após uma observação atenta, focamo-nos em algumas questões mais amplas. Posto isto, li $O$ mito de Narciso e, alguns alunos apontaram o momento em que Oriana viu o seu reflexo no rio e se apercebeu da sua beleza como um dos momentos fundamentais da intriga. Para esta aula planificamos trabalhar o "narcisismo" como conteúdo temático, e pretendíamos problematizar com os alunos várias possibilidades de interpretação deste mito, levando-os a reconhecer a dimensão formativa da obra literária na medida em que se relaciona com aspetos da (nossa) vida quotidiana. Quando questionados sobre os seus conhecimentos relativamente a outras obras com temáticas idênticas, os alunos referiram a obra $\mathrm{A}$ Branca de Neve e classificaram a madrasta como sendo um sujeito profundamente egocêntrico.

Na lição n. ${ }^{\circ}$ 141/142 (plano 15), trabalhou-se a compreensão inferencial e crítica. A palavra "Regicídio" foi escrita no quadro, no início da lição. Os alunos questionaram acerca do seu significado. Não tendo um contexto (uma vez que a palavra foi apresentada isoladamente), queríamos que eles procurassem compreender o sentido da palavra através da sua (de)composição morfológica. Eles chegaram à identificação dos dois radicais presentes (domínio morfológico). Grande parte dos alunos soube explicar o sentido das duas primeiras palavras. Tivemos, no entanto, de ajudá-los a compreender a palavra genocídio. Depois, foi projetada uma imagem da tela "O Regicídio". Tecemos, conjuntamente, uma análise partindo de uma perspetiva mais ampla para uma mais pormenorizada. $\mathrm{O}$ diálogo fluiu sem dificuldades e alguns alunos não tardaram em referir que na tela estava retratada a "morte do Rei", ou seja, a representação do sentido da palavra "regicídio". Seguiu-se a leitura modelar do texto do manual. Os alunos foram convidados a explicitar a sua interpretação do texto, atividade nitidamente facilitada pela anterior exploração da tela. Alguns alunos referiram que os factos narrados no texto surgiam segundo uma ordem cronológica. Foi, então, projetada uma apresentação em Prezi sobre $A$ queda da monarquia. Intencionalmente, escolhi uma apresentação onde estava representada a linha do tempo de forma a irmos localizando os factos que antecederam o desembarque no Terreiro do Paço de um modo cronológico. No momento posterior, os alunos concluíram que o texto literário lido correspondia ao relato e que uma das suas características era a apresentação dos factos segundo uma ordem cronológica. Referimos que a indicação do tempo e do espaço onde ocorreram as ações relatadas são também características desta tipologia textual, assim como a predominância dos verbos no pretérito perfeito do indicativo e das frases declarativas. Quando questionados sobre as frases que se encontravam entre aspas, os alunos mencionaram que tinham sido ditas por pessoas envolvidas nos acontecimentos, referindo que a citação de falas de certas pessoas envolvidas nos factos são também uma das características do relato. Concluídas as características, acrescentamos uma característica adicional, a recorrente presença da enumeração e os alunos procederam aos registos.

$\mathrm{Na}$ lição n. ${ }^{\circ}$ 145/146 (plano 17), continuamos a trabalhar a questão da reorganização da informação. Após a leitura da obra $A$ Viúva e o Papagaio, de Virginia Woolf, realizamos uma atividade de escrita, com os alunos organizados em grupos heterogéneos, cujo objetivo principal era proporcionar-lhes a oportunidade de se manifestarem acerca da compreensão do sentido do texto, tendo particularmente em conta a sequência dos acontecimentos narrados. Solicitamos o preenchimento de uma espécie de esquema. Na primeira fase, os alunos tinham de completar "a linha temporal" dividindo-a nas suas três unidades de significado: situação inicial, desenvolvimento e conclusão. Na segunda fase, deviam completar o esquema, associando a cada unidade de significado os momentos que permitiam situar a ação no tempo e acompanhar (brevemente) o avanço da história. Por fim, na terceira fase, através da escrita de um breve parágrafo, os alunos deviam indicar a mensagem principal da obra. Os alunos tiveram oportunidade de compreender que a informação do texto, deste e de qualquer outro, pode ser estratificada consoante o seu grau de relevância.

Plano de ação - fase C: voltamos a avaliar as competências de compreensão leitora, de identificação e esquematização da informação relevante, através de uma atividade de esquematização. Obtivemos os seguintes resultados:

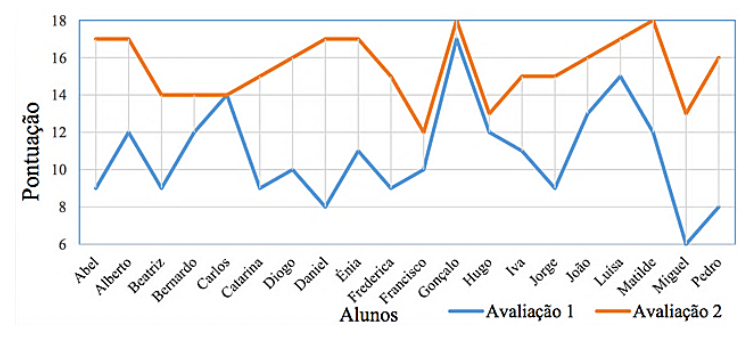

Figura 3. Avaliação das seis categorias de proficiência na realização de esquemas.

Verifica-se uma clara evolução entre a avaliação 1 e 2. Apenas um aluno manteve a sua pontuação. Nenhum obteve uma pontuação inferior a 12 valores e a média da turma subiu para 15.45 valores. Concretamente, na categoria fidelidade, todos elaboraram o esquema respeitando o tema do texto obtendo o máximo de pontos (3). Na categoria distinção, 13 alunos obtiveram 3 pontos e os restantes 7 obtiveram 2 pontos. A respeito da categoria sequencialidade, 13 dos alunos apresentaram a informação hierarquicamente e de um modo lógico, obtendo o máximo de pontos; os restantes 7 obtiveram 2 pontos. Na categoria concisão, houve uma evolução significativa pois apenas 1 aluno foi avaliado com $1 ; 10$ alunos obtiveram 2 pontos e os 9 restantes, 3 pontos. $\mathrm{Na}$ penúltima categoria, integridade, a evolução foi 
igualmente significativa: 12 alunos obtiveram 3 pontos e os restantes 8 obtiveram 2 pontos. Por fim, na última categoria, legibilidade, 9 dos alunos construíram os seus esquemas com cuidado, permitindo o entendimento e a captação do sentido do texto, obtendo 3 pontos; 6 dos alunos obtiveram 2 pontos e apenas 5 obtiveram 1 ponto. Obtidos estes dados, eles foram convertidos nos 5 níveis:

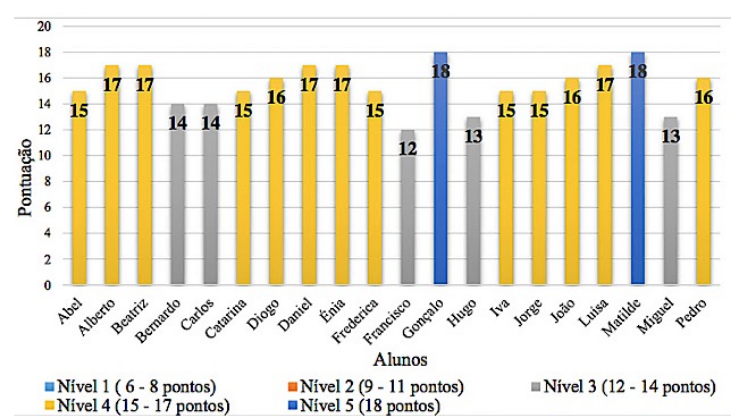

Figura 4 - Conversão da avaliação das seis categorias em níveis.

Esta sistematização permitiu-nos concluir que todos os alunos obtiveram uma avaliação positiva, igual ou superior a 12 pontos. No nível 3 encontravam-se $25 \%$ dos alunos, sendo que ao nível 4 corresponderam $65 \%$, e apenas $10 \%$ atingiu o nível 5 . Importa referir que, no nível quatro, dos 13 alunos que atingiram este nível, 6 eram meninas e os restantes 7 eram rapazes. Por fim, no nível mais alto, o nível 5, encontramos $10 \%$ dos nossos alunos, uma menina e um rapaz. Em suma, na primeira avaliação, $60 \%$ dos alunos encontravam-se no nível 1 e 2 e, na segunda avaliação, $90 \%$ dos alunos conseguiu evoluir e atingir os níveis 3 e 4 . Tendo em consideração os resultados obtidos, consideramos que as EEA que foram realizadas (nesta turma de PES) tiveram um efeito positivo no desenvolvimento de estratégias de recolha e organização da informação relevante. Todavia, a compreensão da leitura, o seu ensino explícito e o devido desenvolvimento requerem tempo e uma ação planeada e alargada no tempo.

\section{Discussão}

Analisamos os dados recolhidos da prática numa linha descritiva e interpretativa. Relembrando as questões relativas às estratégias que os alunos usam em tarefas de compreensão na leitura, nomeadamente na recolha e organização da informação relevante, consideramos que, embora eles saibam alguns dos procedimentos que ajudam a compreender um texto, a recolher e a organizar a informação relevante, não o fazem na prática. No que respeita às estratégias que promovem o desenvolvimento de competências de compreensão da leitura, salientamos que estas visam essencialmente uma prática devidamente pensada e adequada a cada contexto. Assim sendo, o professor deve desenhar uma ação pedagógica com momentos de exploração do texto antes, durante e após a leitura. Ainda a este propósito, consideramos que, para além da comum exploração da compreensão literal, o "pensar sobre o pensar" e a verificação da plausibilidade das suas opções e procedimentos foram consideradas como provas da evolução positiva. De um modo geral, as práticas e intervenções levaram os alunos a fazer esquemas de textos lidos, porque este era um objetivo da investigação: melhorar as capacidades dos alunos para reterem e organizarem informação de um texto, desenvolvendo a sua competência de leitura. Consideramos que estas EEA apresentam um carácter holístico no tratamento de saberes vários. Tentamos articular os conteúdos previstos no Programa de português do ensino básico com os de outras disciplinas, sempre que nos pareceu necessário e enriquecedor da aprendizagem dos alunos.

\section{Referências bibliográficas}

Eco, U. (2005). Obra Aberta: forma e indeterminação nas poéticas contemporâneas. São Paulo: Perspectiva.

Gama, S. (2011). Obras completas de Sebastião da Gama. Lisboa: Editorial Presença.

Giasson, J. (2000). A compreensão na leitura. Lisboa: Edições ASA.

Giasson, J. (2005). La lecture: de la théorie à la pratique. Bruxelles: De Boeck \& Larcier.

Oliveira-Formosinho, J. \& Formosinho, J. (2008). Prefácio: A Investigação-ação e a construção do conhecimento profissional relevante. In L. MáximoEsteves, Visão panorâmica da investigação-ação (pp. 7-14). Porto: Porto Editora.

Reis, C., Dias, A. P., Cabral, A. T. C. C., Silva, E., Viegas, F., Bastos, G., Mota, I., Segura, J., \& Pinto, M. O. (2009). Programa de Português do Ensino Básico. Lisboa: Ministério da Educação - Direcção-Geral de Inovação e Desenvolvimento Curricular.

Ribeiro, I. S., Viana, L. F., Cadime, I. M. D., Fernandes, I., Ferreira, A., Leitão, C., Gomes, C., Mendonça, S. \& Pereira, L. (2010). Compreensão da leitura: dos modelos teóricos ao ensino explícito: um programa de intervenção para o 2. ${ }^{\circ}$ Ciclo do Ensino Básico. Coimbra: Almedina.

Russo, M. (2007). Sebastião da Gama e o seu interesse para a cultura italiana. In João Reis Ribeiro, Sebastião da Gama - O Poeta e o Professor - Estudos e Perspectivas (pp. 81-92). Azeitão: Associação Cultural Sebastião da Gama.

Sá, C. M. (2009). Parecer sobre os novos programas de Língua Portuguesa para o Ensino Básico [Blogue profissional]. Disponível em http://transversalidadescsa.blogspot.pt/2009/02/parece r-sobre-os-novos-programas-de.html.

Sá, C. M. (2014). Estratégias do leitor. Aveiro: Universidade de Aveiro/Departamento da educação [documento policopiado].

Scholes, R. (1989). Protocolos de leitura. Lisboa: Edições 70.

Shulman, L. S. (1987). Knowledge and teaching: Foundations of the new reform. Havard Educational review. 57(1) (pp. 1-21).

Sim-Sim, I. (2006). Ler e ensinar a ler. Porto: Asa Editores.

Sim-Sim, I., Duarte, C., \& Micaelo, M. (2007). O ensino da leitura: A compreensão de textos. Lisboa: DGIDC. 
Viana, F. L., Ribeiro, L. S., Fernandes, I., Ferreira, A., Leitão, C., Gomes, S., Mendonça, S. \& Pereira, L. (2010). O ensino da compreensão leitora. Da teoria à prática pedagógica: um programa de intervenção para o $1 .{ }^{\circ}$ Ciclo do Ensino Básico. Coimbra: Almedina.

Vieira, F., \& e Moreira, M. A. (2011). Supervisão e avaliação do desempenho docente: Para uma abordagem de orientação transformadora. Lisboa: Ministério da Educação - Conselho Científico para a Avaliação de Professores. 